\title{
PAUL VIDAL DE LA BLACHE E A FORMAÇÃO DO CAMPO HISTÓRIA DO PENSAMENTO GEOGRÁFICO
}

\section{PAUL VIDAL DE LA BLACHE AND THE MAKING TO THE HISTORY OF GEOGRAPHICAL THOUGHT FIELD}

Guilherme Ribeiro

Doutor em Geografia pela UFF, com estágio doutoral pela Universidade de Paris ï Sorbonne (Paris IV). Pós-Doutorando em Geografia pela UFMG. Professor Adjunto II de Geografia da UFRRJ.

E-mail: geofilos@ig.com.br

Resumo: o objetivo deste artigo é analisar as apropriações do pensamento de Paul Vidal de la Blache no Brasil e na França para, a partir delas, identificar os caminhos e os descaminhos da formação do campo de pesquisas denominado T̃istória do pensamento geográficoò.

Palavras-chave: Vidal de la Blache; história do pensamento geográfico; epistemologia; Brasil; França.

Abstract: the aim of this article is to analyse the appropriations to the Paul Vidal de la Blacheôs thought for, from them, identify ways and detours of the construction the researchôs field called r̃history of geographical thoughtò.

Keywords: Vidal de la Blache; history of geographical thought; epistemology; Brazil; France.

\section{Introdução}

No intuito de refletir sobre as contribuições de Vidal de la Blache à ciência geográfica, dentre as possibilidades abertas para iniciar esse texto ocorreu-nos que seria pertinente sublinhar um dos aspectos mais interessantes ao redor desse geógrafo: os descaminhos percorridos por sua herança intelectual. Nesse caso, nossa análise está incontornavelmente ligada a um elemento, por si próprio, geográfico. Fazemos menção ao fato de que, como estudante de graduação em Geografia no Brasil entre 1998 e 2001 e no âmbito de um estágio doutoral em Paris entre 2007 e 2008, acabamos por construir três opiniões a respeito de como a obra vidaliana vem sendo processada pelos geógrafos no decorrer do século XX. Portanto, reside na conjugação da experiência brasileira e da experiência francesa o molde no qual as linhas a seguir tomarão corpo, cujo intuito também é o de problematizar a construção do campo ñhistória do pensamento geográficoò. 


\section{Vidal de la Blache na Geografia brasileira e na Geografia francesa: apropriações intelectuais constituintes do campo história do pensamento geográfico}

Pensamos não haver dúvidas de que a penetração do marxismo na Geografia brasileira nos anos 70 e 80 foi algo muito mais positivo do que negativo. Embora ainda não dispomos de um amplo e sólido balanço em termos analítico e bibliográfico do ñmovimentoò conhecido como ñGeografia Críticaò ${ }^{1}$, cremos que esse período da trajetória da disciplina tornou-a menos técnica, mais humana e irremediavelmente voltada para questões de cunho político, social e, em certa medida, histórico. Guardadas as devidas proporções, talvez possamos dizer que se antes a Geografia era pensada e praticada ñde cima para baixoò, após a Geografia Crítica a abordagem predominante será a ñde baixo para cimaò ð numa alusão à mudança de perspectiva operada pela historiografia marxista britânica de Dobb, Thompson, Hobsbawm, Hilton e Hill nos anos 50 e 60 perante a historiografia ñoficialò (KAYE, 1989).

Assim, uma das principais referências intelectuais da Geografia Crítica foi o livro La Géographie ça sert, dôabord, à faire la guerre, escrito pelo geógrafo francês Yves Lacoste em 1976. De fato, trata-se de um livro assaz relevante, posto que concentra seus esforços na dimensão política e geopolítica da disciplina. Segundo Lacoste, o passado da mesma ou negligenciava ou mascarava tais dimensões: enquanto de um lado havia uma ñgeografia dos professoresò factual, locacional e mnemônica, de outro existia uma ñgeografia dos Estados-Maioresò forjada à luz de estratégias, planejamento, militarismo e afins. Portanto, era mister denunciar tal operação ideológica, rever a Geografia ensinada nas escolas e investigar as consequências que a Geografia dos Estados-Maiores provocava nas classes menos favorecidas e no Terceiro Mundo (LACOSTE, 1988 [1976]).

Nos domínios da história do pensamento geográfico e da teoria da Geografia, o livro de Lacoste (juntamente com a revista que ele idealiza, a Hérodote [1976]) é incontestavelmente importante, posto que, entre outros aspectos, abre caminho para a inserção de temas referentes ao poder e a política num ambiente intelectual marcadamente conservador como a Geografia francesa (vide CLAVAL, 2000). Além disso, é impetuoso ao abrir um front de batalha com dois gigantes, rechaçando a ausência do espaço em Marx (e os problemas dela resultantes) e a Geografia ñmodestaò do historiador Lucien Febvre, que defendia que ela deveria estudar o solo, e não o

\footnotetext{
${ }^{1}$ As aspas se justificam porque não iremos problematizar se existiu ou não um efetivo movimento, bem como se a expressão Geografia Crítica é a mais adequada para caracterizá-lo. De todo modo, vale consultar os artigos ñAssim se passaram dez anos (A renovação da Geografia no Brasil no período 1978-1988)ò (MOREIRA, 2000) e ñCerta herança marxista: elementos para repensar a geografia críticaò(DINIZ FILHO, 2002).
}

Geo UERJ - Ano 13, no. 22, v. 2, 2º semestre de 2011 p. 232-249 - ISSN 1981-9021 http://www.e-publicacoes.uerj.br/index.php/geouerj 
Estado $^{2}$. Ao mesmo tempo, atestando que a escala é um dos principais nós epistemológicos da Geografia, propõe a ñespacialidade diferencialò, que consiste na idéia de que as escalas estão diretamente interligadas umas às outras e que uma mudança escalar representa uma alteração qualitativa de um dado fenômeno (LACOSTE, 1988 [1976]).

Todavia, na ânsia de contestação e renovação, Lacoste volta suas atenções para aquele que é, até o momento, o principal nome da Geografia francesa: Vidal de la Blache. Ao concentrar sua reflexão em torno da região como se fosse a categoria geográfica por excelência, Vidal teria atuado, segundo aquele, de modo a impedir a análise de outros recortes espaciais. Carregada de descrição porém desprovida de conteúdo político, Lacoste apresenta a região vidaliana como um ñconceito-obstáculoò, uma ñpersonagemò que daria lugar a múltiplas mistificações políticas $ठ$ denominadas por ele de ñgeografismosò (ibidem, pp.59-66). Na eloquência que lhe é peculiar,

ño conceito-obstáculo da ó́egiãoô vidaliana exerceu, em cheio, seus efeitos de bloqueamento, e isso paralisou as pesquisas teóricas que teriam permitido perceber de maneira racional e eficaz as confusões da espacialidade diferencial. Não somente aquela não foi vista (...), mas ela foi negada pela inculcação de uma representação de mundo, feita de uma série de compartimentos bem estanques, quer dizer, dados pela natureza e a história, por Deus, uma vez por todas e nitidamente separados uns dos outros. As regiões, cada uma designada por um nome próprio para melhor acreditar em sua ôndividualidadeổ ${ }^{3}$ (LACOSTE, 1988:192-193 [1976]).

Finalizada a leitura do célebre livro, chega-se à conclusão de que a herança de Vidal não é outra coisa senão maldita; com efeito, há que se desfazer dela o mais rápido possível. E, mesmo que Lacoste tenha admitido, numa edição posterior, a existência de um ñoutroò Vidal de la Blache através da ñdescobertaò do ñesquecidoò livro La France de lôEst (Lorraine-Alsace) ð onde enfim o aspecto geopolítico estaria presente (ibid., pp.113-119) ठ , o que permaneceu para o leitor foram

\footnotetext{
${ }^{2}$ Para uma investigação da relação de Febvre com a Geografia, interpretando suas críticas a Ratzel e a adesão a Vidal como, entre outras coisas, parte integrante de uma estratégia de delimitação das fronteiras das Ciências Humanas visando a hegemonia da História, vide Ribeiro (RIBEIRO, 2009), assim como outras abordagens questionadoras das interpretações febvrianas (CARVALHO, 1997, 1997a; BAKER, 2006 [2003]; GÓMEZ MENDOZA, 2004; CLAVAL, 2007).

${ }^{3}$ Em 1899, quando assume a cadeira de geografia na Sorbonne, Vidal não poderia ser mais explícito acerca da interdependência escalar: ñas regiões se explicam umas pelas outras. Para dar resultado, a pesquisa precisa ser feita em um certo número de regiões ao mesmo tempo. Para compreender as causas dos fatos, é necessário reunir o testemunho de fenômenos que podem estar separados e esparsosò (VIDAL DE LA BLACHE, 1899:101). Em outro exemplo, refletindo especificamente sobre o impacto da indústria e da cidade na vida regional, mostra como explora o jogo de escalas que atravessa toda sua obra: ñPor todos ou quase todos os lugares têm-se experimentado os efeitos das causas econômicas que, penetrando por todos os lados, submetem tanto a vida agrícola quanto a vida industrial às novas condições nas quais é necessário seguir e, sobretudo, se associar. $\mathrm{O}$ princípio da associação é o que mais contribuiu para transformar a vida regional e dar-lhe mais influência sobre o curso geral da vida nacional. A concentração das indústrias, a solicitação dos mercados estrangeiros, a concorrência e as demandas das aglomerações urbanas reclamam uma organização relacionada à extensão das necessidades e às dificuldades dos meios para executá-las (...) Quando se trata de região, não é muito necessário procurar limites. É mister concebê-la como uma espécie de auréola, que se estende sem limites bem determinados, que encerra e avançaò (VIDAL DE LA BLACHE, 1917a:105-106).
}

Geo UERJ - Ano 13, no. 22, v. 2, 2º semestre de 2011 p. 232-249 - ISSN 1981-9021

http://www.e-publicacoes.uerj.br/index.php/geouerj 
as duras reprimendas dirigidas ao autor do Tableau géographique de la France (VIDAL DE LA BLACHE, 2007 [1903]).

Ainda no Brasil ${ }^{4}$, na revista Geographia, do Programa de Pós-Graduação em Geografia da Universidade Federal Fluminense, Rogério Haesbaert iniciara relevante trabalho de tradução na seção ñNossos Clássicosò. Dentre os artigos vertidos para o português encontravam-se principalmente os de Vidal, com destaque para ñA Geografia Política. A propósito dos escritos de Friedrich Ratzelò (VIDAL DE LA BLACHE, 2002 [1898]) e ñO Princípio da Geografia Geralò (VIDAL DE LA BLACHE, 2002 [1895-1896]). Ambos desvelavam um geógrafo interessado em temas políticos e teóricos. Antes de ir diretamente aos arquivos parisienses, ainda tivemos acesso pela internet ao texto $\partial$ praticamente inédito e quase nunca citado $\partial$ ñRoutes et chemins de lâncienne Franceò, revelador de uma faceta vidaliana, para nós, surpreendente: a cultura (VIDAL DE LA BLACHE, 1996-97 [1902]).

Assim, pouco a pouco, a imagem que tínhamos de Vidal de la Blache começava a ser desfeita. Em Paris, o acesso à biblioteca do Instituto de Geografia da Sorbonne ð onde lecionara nosso investigado ð, bem como os arquivos da biblioteca do grupo de estudos Épistémologie et histoire de la géographie (EHGO), foi crucial, com destaque para os artigos e as resenhas publicadas por aquele nos Annales de Géographie. Fundado ao lado de Marcel Dubois em 1891 (ROBIC, 1993), neste periódico pudemos perceber que a riqueza, a complexidade e a pluralidade da obra de Vidal contrastavam brutalmente com aquilo que outrora havíamos aprendido. De fato, as menções feitas a Vidal no Brasil confinam-se ao texto ñAs características próprias da Geografiaò(VIDAL DE LA BLACHE, 1982 [1913]) e ao livro ñ̃rincípios de Geografia Humanaò (VIDAL DE LA BLACHE, 1954 [1921]), edição póstuma organizada e publicada por seu genro, o geomorfólogo Emmanuel de Martonne.

Some-se a isso o enorme impacto da interpretação lacosteana entre nós e o que temos é um quadro onde Vidal soava como uma grande caricatura; no limite, era praticamente um ñmal necessárioòdos cursos de História do Pensamento Geográfico. E, como se não bastasse, vinculado repetidas vezes ao debate forjado por Febvre opondo um suposto possibilismo vidaliano a um igualmente suposto determinismo ratzeliano (FEBVRE, 1991 [1922]), tudo parecia contribuir para o empobrecimento de sua obra. Uma obra que surgia ali, diante de nossos olhos, nas páginas principais mas também nas páginas cachées dos Annales de Géographie, cada vez mais inusitada.

\footnotetext{
${ }^{4}$ Sobre a apropriação de Vidal feita pela Geografia brasileira, cumpre destacar Acerca da geografia, da política, da geograficidade: fragmentos metodológicos, de Vânia Vlach. Publicado em 1999 pela revista Sociedade \& Natureza, no entanto só fomos conhecê-lo no início de 2011 (da bibliografia então consultada, infelizmente ele não havia sido citado), graças a uma conversa com a própria autora ð que, gentilmente, enviou-nos a revista. Fica aqui o registro $\delta$ e, evidentemente, a indicação de leitura $ठ$ de que tal artigo foi, entre nós, um dos primeiros a apontar as dimensões política e geopolítica em Vidal de la Blache (VLACH, 1999:97-109).
}

Geo UERJ - Ano 13, nº. 22, v. 2, 2º semestre de 2011 p. 232-249 - ISSN 1981-9021 http://www.e-publicacoes.uerj.br/index.php/geouerj 
Sim: a palavra mais adequada talvez seja mesmo essa: inusitada. Afinal, embora no fundo desconfiássemos daquela imagem homogênea e sem contradições projetada por Febvre, Lacoste e outros, efetivamente jamais imagináramos des-cobrir um geógrafo profundamente interessado por matérias as mais diversas como interdisciplinaridade, história, economia, sociologia, política e, sobretudo, epistemologia e geopolítica.

Esses dois últimos tópicos merecem ser separados por, pelo menos, duas razões: em primeiro lugar, existe um discurso recorrente que sustenta a insuficiência ou mesmo um desdém epistemológico que caracterizariam a ciência geográfica (SCHAEFFER, 1953; DOSSE, 2007 [1992]; SANTOS, 1978; QUAINI, 1979). Esta é uma versão que nos parece absolutamente insustentável. De Vidal a Hartshorne, de Hettner a Sauer, passando por geógrafos que se dedicaram à história do pensamento geográfico (CAPEL, 1981; CLAVAL, 1998; BUTTIMER, 1980; LIVINGSTONE, 1992; GOMES, 1996; GODLEWSKA, 1999) até chegar a um grupo que só consegue pensar a Geografia à luz de um intenso e profícuo debate teórico-metodológico (GREGORY, 1999; SANTOS, 1996; MASSEY, 2008 [2005]; SOJA, 1993 [1989]; SMITH, 1988 [1984]; CLAVAL, 2001; HARVEY, 1992 [1989]; WERLEN, 1995), defender a idéia de uma carência epistemológica que desvalorizaria a Geografia no âmbito das Ciências Humanas ou demonstra um profundo desconhecimento da história da disciplina, ou faz parte de um projeto que visa hegemonizar a visão geográfica de uma dada corrente em detrimento das demais. Como se não bastasse, ao observarmos o diálogo entre as Ciências Humanas e a Geografia no decorrer do século XX, percebe-se claramente uma interpretação ingênua e equivocada ao redor da produção geográfica ð proveniente sobretudo da Sociologia e da História ð, que tão somente engrossou o coro daquela versão (SIMIAND, 1909; FEBVRE, 1991 [1922]; BOURDIEU, 1980; CHARTIER, 2002 [1980]; SODRÉ, 1976).

Em segundo lugar, assim como a epistemologia, o tema geopolítica precisa ser sublinhado, seja porquê está presente com vigor no pensamento de Vidal ${ }^{5}$ (ainda que tenha sido amplamente negligenciado), seja porquê também foi alvo de distorções de fundo nacionalista e ideológico. Conforme assinala Soja, para as Ciências Sociais tudo o que dizia respeito à Geografia estava ligado ou determinismo ou à geopolítica (SOJA, 1993 [1989]). Nessa conjuntura, jogaram papel de

\footnotetext{
${ }^{5}$ São exemplos de reflexões geopolíticas a questão das fronteiras e das nacionalidades européias; a dificuldade francesa ao lidar com as porosas fronteiras das colônias africanas; o diálogo com Ratzel; a contenda reunindo Brasil e França ao redor de uma fração do território da Guiana; os desdobramentos econômicos, políticos e geográficos da missão militar francesa no Peru; a necessidade de uma participação ativa da França na confecção da carta internacional do mundo à escala milionésima; e a ampla mirada estratégica sobre a Europa durante a I Guerra Mundial (VIDAL DE LA BLACHE, 1889, 1897, 1898; 1901, 1902a; 1906; 1910; 1917). Para uma análise da dimensão geopolítica em Vidal, consulte Sanguin (SANGUIN, 1988) e Ribeiro (RIBEIRO, 2010, 2010a).
}

Geo UERJ - Ano 13, nº. 22, v. 2, 2º semestre de 2011 p. 232-249 - ISSN 1981-9021 http://www.e-publicacoes.uerj.br/index.php/geouerj 
relevo as duras reprimendas de Febvre à obra que considerava uma espécie de ñmanual do imperialismo alemãoò (Politische Geographie, de Ratzel [FEBVRE, 1991:53 [1922]) e, na sequência, os vínculos envolvendo a teoria do ñespaço vitalò desse geógrafo à expansão territorial promovida pelo III Reich $\succsim$ vínculos que, como sabemos, não partiram do próprio Ratzel, mas sim daqueles que se consideravam seus sucessores (cf. SANGUIN, 1990). Evidentemente, nem Febvre e, posteriormente, nem os estudiosos do pensamento geográfico na França se empenharam em perquirir os laços que uniam a École Française de Géographie ao Colonialismo e às questões geopolíticas que afligiam o continente europeu (cf. RIBEIRO, 2010a). Não por acaso La France de lôEst: Alsace-Lorraine, de Vidal (VIDAL DE LA BLACHE, 1994 [1917]), passou todo o século XX repousando recôndito e tranquilo nas caves do Hexágono... (RIBEIRO, 2011).

Eis a surpresa de nossa experiência francesa: percebemos que investigar a dimensão geopolítica da Geografia Clássica era um verdadeiro tabu. Mais curioso ainda era evidenciar o brutal contraste entre a profusão de artigos dedicados ao tema nas páginas dos Annales e a ausência quase que total de livros versando sobre o assunto. Tudo indica que o rico capítulo $L e$ mouvement colonial, de Vincent Berdoulay, presente no livro La formation de lấcole française de Géographie, foi o pioneiro nesse debate (BERDOULAY, 1995:45-75 [1981]). Porém, teríamos novamente um longo intervalo até o final da década de 90, quando da publicação de Imaginaire, science et discipline, de Olivier Soubeyran, disposto a interrogar algumas ausências ð a Geografia Colonial na gênese da revista Annales de Géographie, por exemplo ð no seio da história do pensamento geográfico francês (SOUBEYRAN, 1997). Esse ñmovimentoò parece ter tomado força nos últimos anos, com destaque para duas obras recentes: LôEmpire des géographes. Géographie, exploration et colonisation (XIXe-XXe siècles), dirigido por Pierre Singaravélou (SINGARAVÉLOU, 2008), e Géographes en Algérie (1880-1950). Savoirs universitaires en situation coloniale, de Florence Deprest (DEPREST, 2009).

Esboçado esse quadro, as perguntas-chave a serem feitas são as seguintes ${ }^{6}$ : ontem e hoje, quem são os responsáveis pela história do pensamento geográfico francês? Quais são seus alinhamentos políticos? Quais as razões explícitas e implícitas que os levaram a ler a Escola Francesa de Geografia como uma corrente a-política?

Como vimos, uma parte destas respostas deve ser localizada externamente $\succsim$ sobretudo entre os historiadores, que legitimaram o discurso febvriano ao reproduzi-lo ipsis litteris. O outro

\footnotetext{
${ }^{6}$ Devemos ao conceito de campo, desenvolvido pelo sociólogo francês Pierre Bourdieu, bem como à noção de ordem do discurso, do filósofo francês Michel Foucault, a orientação das interrogações aqui levantadas (BOURDIEU, 2002 [1985]; FOUCAULT, 2004 [1970]). Na Geografia, o argentino Marcelo Escolar promove uma fértil aproximação com tais autores, resultando deste encontro o importante livro Crítica do discurso geográfico (ESCOLAR, 1996 [1993]).
}

Geo UERJ - Ano 13, nº. 22, v. 2, 2º semestre de 2011 p. 232-249 - ISSN 1981-9021 http://www.e-publicacoes.uerj.br/index.php/geouerj 
lado dessa equação encontra-se numa determinada atitude: cabe aos geógrafos fazer valer o lado político de sua história.

\section{Vidal de la Blache: interpretações}

Uma outra abordagem da obra vidaliana não só é possível como necessária. Afinal, diante de pensamento tão complexo, não podemos nos deixar convencer de que ñudo já foi ditoò a seu respeito. Na realidade, existe uma questão de fundo por trás de um suposto ñesgotamentoò ou ñconsensoò ao redor de Vidal: já está mais do que na hora da Geografia passar a ter uma outra atitude diante de seus clássicos. Nisso, temos muito a aprender com a Sociologia, a Antropologia, a Biologia e a Psicologia, que os reconhecem como fundamentos de seus ofícios, e não como páginas enfadonhas e irrelevantes do passado. Acaso seria imaginável um biólogo abrir mão de estudar Darwin? Um psicólogo deixar de analisar a obra de Freud? Um economista desconhecer Marx?

Tal postura dos geógrafos têm a ver também com a estreita visão acerca do significado que o processo histórico assume no interior da disciplina. Aqui, dois fatores entram em cena: o primeiro versa sobre o fato de que a Geografia estuda, fundamentalmente, o tempo presente. Assim, na maioria das vezes, esquecemos da premissa simples e basilar de que passado, presente e futuro são indissociáveis (isso para nos limitarmos a esses recortes temporais mais comuns), de modo que não enxergamos outra coisa senão o século $\mathrm{XX}$ em diante. Outro fator indica a hegemonia do historicismo no pensamento moderno, historicismo esse que atuou como verdadeiro obstáculo na incorporação da espacialidade quer à vida social, quer à epistemologia (SOJA, 1993 [1989]). Com efeito, tendemos a pensar que tudo o que se refere ao passado e à história seja antigeográfico, anti-espacial. Ambos configuram um quadro que urge reverter: o sentido e a importância do processo histórico de constituição do campo geográfico vão, quase sempre, por água abaixo.

Portanto, admitindo o legado de Vidal como aberto à inspeção e à renovação em virtude dos dilemas e das inquietações colocados pelo presente em relação ao passado, temos ensaiado construir, ainda que de maneira embrionária, um caminho analítico em torno da Geografia de Vidal de la Blache (RIBEIRO, 2007, 2008, 2010, 2010a, 2010b, 2011, 2011a). Está mais do que na hora de ultrapassarmos uma leitura simplista de uma vertente geográfica francesa que se opunha ao germanismo imperialista. Para tanto, tal como expressamos noutra ocasião, devemos compreendê-la sobretudo como um q́aradigmaôde uma era, que recolhe e examina as grandes questões que afligiam a Europa de então. A saber: descrição, mapeamento e exploração do Geo UERJ - Ano 13, nº. 22, v. 2, 2º semestre de 2011 p. 232-249 - ISSN 1981-9021 http://www.e-publicacoes.uerj.br/index.php/geouerj 
ambiente; papel da cidade como intensos centros de influência e da circulação ñdesterritorializandoò antigas raízes camponesas na organização espacial do mundo moderno; conflitos entre Estados territoriais. Além disso, ela é paradigmática não apenas no campo temático, mas também no campo metodológico: mesmo com o progresso dos transportes e das comunicações a superar distâncias e adversidades naturais; no instante em que noções como proximidade e distância, interior e capital, pays e região sofriam profundas transformações, redefinindo suas formas e seus conteúdos; e quando os princípios naturalistas que regiam a découpage do mundo eram substituídos por outros critérios, isso não significava, em hipótese alguma, a irrelevância do espaço e do território. Sua démarche incorporava o resgate do passado na elucidação do presente, a dependência das regiões umas às outras e as diferenças fisionômicas entre elas. Em torno do princípio da unidade terrestre e para além da mera quantificação da escala, eram indissociáveis o local e global, a parte e o todo, o detalhe e o conjunto (RIBEIRO, 2010b).

Nessa proposta $\succsim$ que dialoga principalmente com trabalhos escritos a partir dos anos 90, tais como MERCIER, 1995, 1998, 2001; BONNEFONT, 1993; OZOUF-MARIGNIER \& ROBIC, 1995, 2000; OZOUF-MARIGNIER, 2000; ROBIC，1993，2000，2004; SOUBEYRAN，1997; CLAVAL, 1998, 2001, 2007 , enfatizamos um Vidal de la Blache preocupado com questões epistemológicas, e não um empirista naif; atento às metamorfoses sociais e econômicas que implicavam em novos delineamentos e novas concepções do recorte regional, e não um dogmático preso a uma única escala cuja existência seria fixa e incontestável; analista do mundo urbanoindustrial e seus desdobramentos espaciais, e não somente um ruralista; amplamente ligado à conjuntura geopolítica referente ao Hexágono e ao Império Francês (e, portanto, à escala mundo, não havendo assim dicotomia entre Geografia Geral e Geografia Regional), e não um cientista alheio à esfera política. Não obstante, o que dizer de seus esforços visando a delimitação e a edificação da Geografia Humana, com realce para o artigo ñLa géographie humaine. Ses rapports avec la géographie de la vieò ?(VIDAL DE LA BLACHE, 1903a, mas também 1903, 1904, 1912).

Além disso, estamos diante de um geógrafo que aperfeiçoou um método de investigação bastante rico para a época, contemplando sobremaneira os seguintes pontos:

(i) correlação, encadeamento e articulação entre as partes e o todo, reconhecendo aspectos particulares porém sempre atrelados à unidade terrestre $\succsim$ principal item metodológico de Vidal. Em suas próprias palavras:

A idéia de que a Terra é um todo, no qual as partes estão coordenadas, proporciona à Geografia um princípio de método cuja fecundidade aparece melhor à medida que se amplia a sua aplicação. Se nada existe isoladamente no organismo terrestre, se em todo lugar repercutem as leis gerais, de modo que não

Geo UERJ - Ano 13, no. 22, v. 2, 2º semestre de 2011 p. 232-249 - ISSN 1981-9021 http://www.e-publicacoes.uerj.br/index.php/geouerj 
se possa tocar uma parte sem provocar todo um encadeamento de causas e de efeitos, a tarefa do geógrafo toma um caráter diferente daquele que às vezes lhe é atribuído. Qualquer que seja a fração da Terra que estude, ele não pode nela se fechar. Um elemento geral se introduz em todo estudo local. Não há de fato área em que a fisionomia não dependa de influências múltiplas e longínquas das quais importa determinar o local de origem. Cada área age imediatamente sobre sua vizinha e é influenciada por ela. Fora mesmo de toda relação de vizinhança, a ação cada vez melhor reconhecida de leis gerais se traduz por afinidades de formas ou de climas que, sem alterar a individualidade própria de cada área, marca-a com características análogas. Estas analogias ou ñconformidadesò, seguindo o termo muito conhecido de Bacon, desde que o homem começou a dominar o conjunto dos fenômenos terrestres, chamaram a sua atenção. Muitas podem ser apenas aparentes, mas outras são reais; elas são fundadas, não sobre puros encontros exteriores, mas sobre relações de origem e de causas. Entre estas a aproximação se impõe, pois cada uma proporciona à outra seu tributo de explicação. O geógrafo é levado assim a projetar sobre o objeto que estuda todo o esclarecimento fornecido pela comparação de casos análogos (idem, p.129).

(ii) a natureza como fonte de inspiração em termos de totalidade, dinamismo, coordenação e estabilidade/mudança (no que tange à temporalidade), enfatizando assim os métodos das Ciências Naturais. Para ele, a geografia humana merece esse nome porque

ñestuda a fisionomia terrestre modificada pelo homem; nisso ela é geografia. Ela não encara os fatos humanos senão em sua relação com a superfície onde se desenvolve o drama múltiplo da concorrência dos seres vivos. Há, portanto, fatos sociais e políticos que não entram em sua competência, que se ligam a ela apenas indiretamente e, assim, não há porquê ela se ocupar deles. A despeito desta restrição, ela mantém inúmeros pontos de contato com essa ordem de fatos. No entanto, este ramo da geografia tem a mesma origem que a geografia botânica e zoológica. É delas que ela extrai sua perspectiva. O método é análogo, porém bem mais delicado na manipulação ठ como em toda ciência onde a inteligência e a vontade humanas estão em jogoò (VIDAL DE LA BLACHE, 1903:223-224, grifo nosso exceto a palavra ñgeografiaò no alto do parágrafo).

(iii) interdisciplinaridade de vanguarda, transitando com habilidade pela Ecologia,

Geologia, Etnografia, Sociologia e História numa abordagem que pregava a unidade das ciências e, portanto, rejeitava a fragmentação típica da Ciência Moderna. Segundo ele,

ñas ciências da terra, e mesmo certas ciências do homem, acusam uma tendência a se desenvolver em um sentido mais geográfico. Esta tendência é derivada das próprias necessidades de sua evolução. Em seu avanço, elas tem reencontrado a Geografia em seu caminho. Tudo isso é, na realidade, a expressão da unidade fundamental que as religa. A relação entre elas não consiste em simples transferência de resultados, mas no fato de que estão mutuamente impregnadas em seus métodosò(VIDAL DE LA BLACHE, 1899:107, grifo nosso). 
(iv) comparações sociológicas, culturais, geográficas e históricas, o que significa também intensa exploração dos processos históricos;

(v) trabalhos de campo, observação direta das paisagens, relevância da cartografia, pesquisas em arquivos, uso de estatísticas e relatórios administrativos ${ }^{7}$, sem com isso deixar de reconhecer os saberes geográficos populares;

(vi) onipresença da tradição alemã de Humboldt, Ritter, Ratzel e, em menor medida, Peschel.

A título de síntese do que representa a epistemologia geográfica vidaliana, sugeriríamos que trata-se de um tipo original de démarche (nunca claramente enunciada desta forma) que, indo do território (em sua acepção mais física) ao homem e retornando ao território (agora modificado), admite um triplo movimento, capaz de distinguir a Geografia das demais ciências:

1. o epistemológico, concernente à relação homem-meio e seus desdobramentos;

2. o histórico, atinente à transformação humana da natureza através da técnica e da cultura; e

3. o político, incidindo nas disputas espaciais promovidas, notadamente, por Estados Nacionais e Impérios.

Trazendo as contribuições de Vidal de la Blache para os nossos dias, parece que a Globalização acabou por lhe dar razão, uma vez que defendia a unidade terrestre e a interdependência dos fenômenos como pilares epistemológicos da Geografia (VIDAL DE LA BLACHE, 1894, 1896, 1899, 1912). Atualmente, quem, em sã consciência, pretende explicar o mundo fora dessa perspectiva? Porém, não é só isso: face a um pensamento que jamais dicotomizou homem e natureza; que destacou a paisagem como reveladora das dinâmicas presente e pretérita de um dado lugar; que sempre refletiu a Geografia a partir da interlocução com as demais ciências; e que grifou o papel das técnicas e da circulação nas mudanças do meio e na

\footnotetext{
${ }^{7}$ Eis aqui um registro interessante: enquanto a História ainda via os documentos escritos e oficiais como únicos dignos de fé, há tempos Vidal utilizava uma gama de fontes de pesquisa, que iam de relatórios militares, administrativos e de expedições a mapas antigos, estatísticas e observação das paisagens. Não por acaso, Vidal seria uma das matrizes do processo de renovação historiográfica promovido pelos Annales de Bloch e Febvre a partir de 1929. Tal renovação possui na ampliação e no questionamento das fontes um de seus principais traços. Todavia, aqui há que se grifar o que é, no mínimo, uma curiosidade desconcertante, embaraçosa. Se entre os historiadores Vidal ganharia destaque, do lado dos geógrafos ocorreria o oposto: enquanto aqueles que se consideravam seus seguidores empobreciam seu legado (CLAVAL, 1998), as novas correntes o interpretariam como démodé... Sob esse ponto de vista, a trajetória do pensamento geográfico tem mostrado um desvio: ao invés de acumular tradições, métodos e conhecimentos, aperfeiçoando-os, cada corrente/geração deseja inventar a própria roda...
}

Geo UERJ - Ano 13, no. 22, v. 2, 2º semestre de 2011 p. 232-249 - ISSN 1981-9021

http://www.e-publicacoes.uerj.br/index.php/geouerj 
organização do espaço (VIDAL DE LA BLACHE, 1903a, 1908, 1902, 1911, 1911a, 1905), não restam dúvidas de que Vidal influenciou as gerações posteriores muito mais do que elas mesmas admitiram ð cuja ânsia de ruptura nem sempre era acompanhada de avanços teóricometodológicos vigorosos, tal como pode-se constatar a propósito da New Geography e de uma certa marxificação dos conteúdos geográficos levada adiante pela Geografia Crítica.

Além disso, sua herança epistemológica nos parece bastante atual, e, guardadas as devidas proporções, mantém certa correspondência com determinadas orientações da pesquisa contemporânea.

\section{Conclusão: a renovação dos estudos geográficos passa, necessariamente, por uma} ampla e irrestrita apreciação das heranças epistemológica e política da disciplina

Dentre os livros em língua portuguesa que marcaram a geração de estudantes de Geografia no Brasil das décadas de 80 e 90, um deles intitulava-se $O$ que é Geografia. Fruto do diálogo que geógrafos brasileiros travavam com o marxismo, pelo menos, desde a década de 70, Ruy Moreira abria seu texto a partir da Conferência Internacional de Geografia (1876) e do Congresso de Berlim (1884-1885) ठ idealizadas, respectivamente, pelo rei belga Leopoldo II e pelo prussiano Bismarck ð, ocasiões em que as potências imperialistas européias discutiram a partilha da África e da Ásia. No intuito de recontar a história da Geografia frisando criticamente seus componentes históricos e ideológicos, Moreira escreveu algo importante mas que, aparentemente, passou em branco: o medo dos geógrafos brasileiros de olhar para o espelho ${ }^{8}$. Se a ênfase nos geógrafos brasileiros é facilmente explicada pela conveniência de parte deles com o regime de exceção que assolava o país, não sem maiores dilemas podemos estender tal medo à corporação em escala mundial (MOREIRA, 1980).

Uma ciência precisa estar permanentemente aberta à inspeção. No entanto, os campos científicos não são espaços ilimitados de produção de conhecimento, acessíveis a novas idéias que acumular-se-iam ao sabor do saber. Em sua totalidade, as ciências não possuem um projeto comum a fim de, p.ex., aperfeiçoarem seus instrumentos de compreensão da realidade $ठ$ que, entretanto, é una. Ao contrário: fundadas sob o paradigma da diferença (FOUCAULT, 1999 [1969]), excluem-se mutuamente e afirmam constantemente suas particularidades, como se tais procedimentos fossem

\footnotetext{
${ }^{8}$ ñOs historiadores da geografia, quando se remetem ao que ela tem sido, não fazem mais do que esconder, sob uma pitada superficial de crítica, o significado e a extensão do seu comprometimento real. Fazem-no descritivamente, sob o mesmo modo como produzem o conhecimento geográfico. Talvez por isso a geografia seja um saber tão desprovido de historiadores e de crítica interna (...) Tudo parece indicar que os geógrafos brasileiros têm medo de se verem no espelhoò(MOREIRA, 1980:13).
}

Geo UERJ - Ano 13, nº. 22, v. 2, 2º semestre de 2011 p. 232-249 - ISSN 1981-9021

http://www.e-publicacoes.uerj.br/index.php/geouerj 
uma condição inalienável para sua própria reprodução. Além de, em geral, desconfiarem umas das outras, permanecem alertas àquilo que lhes pareça inusual ou avant-garde seja no interior ou no exterior de suas circunscrições. Assim, uma leitura em torno de um campo científico não se encerra apenas no exame daquilo que foi/é incluído em sua agenda de pesquisas; ela deve incorporar os aspectos que não puderam ser ñconciliadosò e, com efeito, foram excluídos e deslocados segundo determinados padrões (supostamente científicos) mantidos pelo discurso vigente. Daí a prioridade a ser dada aos condicionantes sociais que traçaram as linhas-mestras desta ou daquela ciência, sobretudo quando a problemática analisada versar sobre sua conformação epistemológica, já que esta, revestida de uma suposta superioridade atribuída à teoria e ao método, quer repelir qualquer traço político, econômico e ideológico que venha maculá-los.

Desta maneira, a forma como a história do pensamento geográfico vem sendo operada ilustra, exemplarmente, as carências, potencialidades e divergências em torno do ofício do geógrafo. É, portanto, arena de conflito e tensão. Em defesa de uma história do pensamento geográfico aberta ao diálogo com outras disciplinas e conectada à dinâmica político-social, o geógrafo italiano Massimo Quaini sofreu na pele os desafios de tal tarefa. Por ocasião de um concurso para lecionar História da geografia e dos exploradores na faculdade de Gênova, não obteve êxito. O argumento: seu livro Marxismo e Geografia (QUAINI, 1979) dizia respeito mais à história das doutrinas políticas que à da geografia (QUAINI, 1983:11). Se declarar que a geografia serve para desvendar máscaras sociais (MOREIRA, 1978) é um importante apelo à responsabilidade política do fazer geográfico, nem por isso deixa de soar como discurso corporativo, na medida em que outras disciplinas também podem fazê-lo e que não há nada que comprove que a Geografia o faça melhor que as outras (cf. ESCOLAR, 1993:36-37). Igualmente, o que dizer da chamada de que ña geografia está em toda a parte?ò (COSGROVE, 1998 [1989]), senão reconhecê-la, no mínimo, como de uma exultante ingenuidade?

Dito isso, cremos ser plausível alegar que uma das funções dos estudos em torno do pensamento geográfico reside na análise da relação entre o discurso e a prática situados em seu contexto histórico. Todo saber contém, em si, o germe de uma prática que, ora o discurso a revela, ora a oculta. É a esse jogo de luz e de sombra que cabe descortinar (RIBEIRO, 2009a). Em outras palavras, a problematização a ser levantada pode ser assim enunciada: quais os papéis sociais que os conceitos, temáticas e métodos que constituem a epistême da Escola Francesa de Geografia ठ e, em particular, a obra de Vidal de la Blache ठ representaram entre o final do século XIX e a 
primeira metade do século XX? Sim, pois o saber pelo saber, a ñteoria teóricaò ${ }^{9}$ que se fecha nela mesma, são ferramentas insuficientes para a compreensão da trajetória de qualquer ciência, visto que esta não se legitima apenas entre seus pares. Quando o geógrafo norte-americano Richard Hartshorne atesta que a Geografia é o que os geógrafos dela fizeram (HARTSHORNE, 1978 [1959]), há que relativizá-lo, acrescentando que a Geografia é que historiadores, sociólogos, geólogos, geomorfólogos e o campo científico lato sensu dela fizeram. Logo, seu percurso deve ser contemplado enquanto um incessante processo de cruzamento, interface e interseção, mutável ao longo do tempo e conforme o desenvolvimento das ciências em cada país.

Além disso, ela só adquire pleno sentido quando legitimada socialmente. Antes de produtos intelectuais, as ciências são produtos sociais. Isto quer dizer que a gênese, a maturidade e o ocaso das mesmas devem-se tanto aos esforços de seus representantes quanto às demandas colocadas pela vida social. Se os geógrafos, de forma geral, possuem dificuldades em atrelar traços como a relação homem-meio, os trabalhos de campo e a descrição regional à trágica dominação imperialista, às ambições capitalistas e ao mito da identidade nacional, parte dessa postura deve ser creditada ao temor de estar frente ao espelho. Este espelho, nomeado história, e, portanto, refletor do passado, inevitavelmente conduz o geógrafo à auto-análise. A imagem observada inibe tanto um presente otimista quanto um futuro promissor. Nele, os geógrafos vêem parte daquilo que querem olvidar, posto que há certas coisas das quais ele é incapaz de se orgulhar.

\footnotetext{
${ }^{9}$ Definida por Bourdieu como ñdiscurso profético ou programático que tem em si mesmo o seu próprio fim e que nasce e vive da defrontação com outras teoriasò (BOURDIEU, 2002:59 [1985]).

Geo UERJ - Ano 13, nº. 22, v. 2, 2º semestre de 2011 p. 232-249 - ISSN 1981-9021

http://www.e-publicacoes.uerj.br/index.php/geouerj
} 


\section{Referências Bibliográficas}

BAKER, Alan. Geography and History: Bridging the Divide. Cambridge: University Press (2006 [2003]).

BERDOULAY, Vincent. La formation de lấcole française de géographie. Paris: Éditions du CTHS (1995 [1981]).

BONNEFONT, Jean-Claude. La Lorraine dans l'oeuvre de Paul Vidal de la Blache. In: CLAVAL, Paul (dir.). Autour de Vidal de la Blache. La formation de lấcole française de Géographie. Paris: Éditions du CNRS (1993).

BOURDIEU, Pierre. Lâdentité et la représentation. Éléments pour une réflexion critique sur lâdée de région. Actes de la recherche en Sciences Sociales, vol. 35, n.35 (1980).

ઇ $\succsim$. A gênese dos conceitos de habitus e de campo. In: BOURDIEU, Pierre. O poder simbólico. $5^{\text {a }}$ ed. Rio de Janeiro: Bertrand Brasil (2002 [1985]).

BUTTIMER, Anne. Sociedad y medio en la tradición geográfica francesa. Barcelona: Oikos-Tau (1980).

CAPEL, Horacio. Filosofía y Ciencia en la Geografía Contemporánea. Barcelona: Barcanova (1981).

CARVAlHO, Marcos de. Diálogos entre as Ciências Sociais: um legado intelectual de Friedrich Ratzel (1844 ï 1904). Biblio 3W. Revista de Geografia y Ciencias Sociales, $\mathrm{n}^{\mathbf{0}} 34$ [http://www.ub.es/geocritic/b3w-34.htm] (1997).

Ratzel: releituras contemporâneas. Uma reabilitação? Biblio 3W. Revista de Geografia y Ciencias Sociales, $\mathrm{n}^{\circ} 25$ [http://www.ub.es/geocritic] (1997a).

CHARTIER, Roger. A história entre geografia e sociologia. In: CHARTIER, Roger. À beira da falésia. A História entre certezas e inquietude. Porto Alegre: Ed. Universidade/UFRGS (2002 [1980]).

CLAVAL, Paul. Histoire de la Géographie française de 1870 à nos jours. Paris: Nathan (1998).

ઇ $\succsim$. Hérodote and the french left. In: ATKINSON, David, DODDS, Klaus (ed.). Geopolitical traditions : critical histories of a century of geopolitical thought. London: Routledge (2000).

ð ð ઇ . Épistémologie de la Géographie. Paris: Nathan (2001).

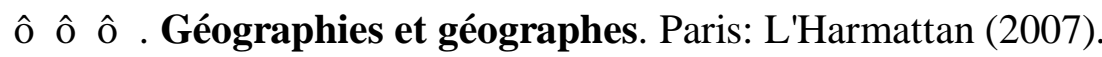

COSGROVE, Denis. A Geografia está em toda parte: cultura e simbolismo nas paisagens humanas. In: CORREAA, Roberto Lobato, ROSENDAHL, Zeny (orgs.). Paisagem, tempo e cultura. Rio de Janeiro: EDUERJ (1998 [1989]).

DEPREST, Florence. Géographes en Algérie (1880-1950). Savoirs universitaires en situation coloniale. Paris : Belin (2009) 
DINIZ FILHO, Luis Lopes. Certa herança marxista: elementos para repensar a Geografia crítica. In: KOZEL, Salete, MENDONÇA, Francisco (orgs.). Epistemologia da Geografia. Florianópolis: Editora da UFSC (2002).

DOSSE, François. A convidada de útima hora: a Geografia desperta para a epistemologia. In: DOSSE, François. História do Estruturalismo: o canto do cisne, de 1967 a nossos dias. Vol.

2. Bauru: Edusc (2007 [1992]).

ESCOLAR, Marcelo. Crítica do Discurso Geográfico. São Paulo: Hucitec (1996 [1993]).

FEBVRE, Lucien. A Terra e a Evolução Humana. Introdução Geográfica à História. $2^{\mathrm{a}}$ ed. Lisboa: Cosmos (1991 [1922]).

FOUCAULT, Michel. A ordem do discurso. $11^{\text {a }}$ ed. São Paulo: Loyola (2004 [1970]).

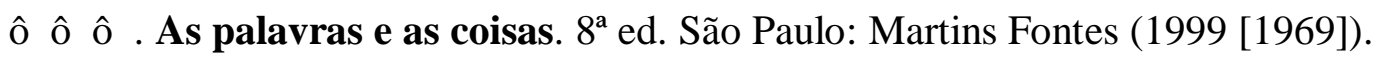

GREGORY, Derek. Exploration in critical human geography. Heidelberg: Department of Geography (1999).

GODLEWSKA, Anne. Geography unbound: French geographic science from Cassini to Humboldt. Chicago: University of Chicago Press (1999).

GOMES, Paulo César da Costa. Geografia e Modernidade. Rio de Janeiro: Bertrand Brasil (1996).

GÓMEZ MENDOZA, Josefina. Geografia e historia, ¿qué relación en la atualidad? Barcelona (no prelo) (2004).

HARTSHORNE, Richard. Propósitos e Natureza da Geografia. São Paulo: Hucitec/EDUSP (1978 [1959]).

HARVEY, David. Condição Pós-Moderna. São Paulo: Loyola (1992 [1989]).

KAYE, Harvey J. Los Historiadores Marxistas Britanicos. Zaragoza: Prensas Universitarias (1989).

LACOSTE, Yves. A Geografia - isso serve, em primeiro lugar, para fazer a guerra. Campinas: Papirus (1988 [1976]).

LIVINGSTONE, David. The geographical tradition. Oxford: Blackwell (1992).

MASSEY, Doreen. Pelo espaço. Uma nova política da espacialidade. Rio de Janeiro: Bertrand (2008 [2005]).

MERCIER, Guy. La région et lốtat selon Friedrich Ratzel et Paul Vidal de la Blache. Annales de Géographie, n. 583 (1995) [Uma versão em português deste artigo foi por nós traduzida na revista Geographia (UFF), vol. 11, n.22 (2009)].

ઇ $\succsim$. Paul Vidal de la Blache ou la légitimation patriotique de la région et de la géographie. Revue française de géoéconomie, n. 5, printemps (1998)

$\succsim \succsim$. Entre science et patrie. Lecture du régionalisme de Paul Vidal de la Blache. Cahiers de Géographie du Québec, vol. 45, n.126, déc. (2001).

MOREIRA, Ruy. A Geografia serve para desvendar máscaras sociais. In: MOREIRA, Ruy (org.). Geografia: teoria e crítica. O saber posto em questão. Petrópolis: Vozes (1978)

ઇ ઇ ઇ . O que é Geografia. São Paulo: Brasiliense (1980).

ઇ ઇ . Assim se passaram dez anos (A renovação da Geografia no Brasil no período de 1978-1988). Geographia (UFF), ano II, nº 3 (2000). 
OZOUF-MARIGNIER, Marie-Vic, ROBIC, Marie-Claire. La France au seuil des temps nouveaux. Paul Vidal de la Blache et la régionalisation. Lânformation Géographique, vol. 59 (1995). [Uma versão em português deste artigo foi por nós traduzida na revista Geographia (UFF), vol. 9, n.18 (2007)].

ઇ ઇ $\succsim$ ઇ . Un Tableau à vif... La réception du Tableau de la géographie de la France de P. Vidal de la Blache. In: ROBIC, Marie-Claire (dir.). Le Tableau de la Géographie de la France de Paul Vidal de la Blache. Dans le labyrinthe des formes. Paris: Éditions du CTHS (2000).

QUAINI, Massimo. A Construção da Geografia Humana. Rio de Janeiro: Paz e Terra (1983).

ð ð ð . Marxismo e Geografia. Rio de Janeiro: Paz e Terra (1979).

RIBEIRO, Guilherme. Geografia Humana: fundamentos epistemológicos de uma ciência. In: HAESBAERT, Rogério, PEREIRA, Sergio Nunes, RIBEIRO, Guilherme (orgs.). Vidal Vidais. Textos de Geografia Humana, Regional e Política. Rio de Janeiro: Bertrand Brasil (2011a) (no prelo).

ઇ ઇ ઇ . A Geografia e o desafio da Modernidade: La France de lôEst (Lorraine-Alsace) cem anos depois. Biblio 3W, vol. XVI, n.934, 30 de julio (2011). http://www.ub.edu/geocrit/b3w934.htm

ઇ $\succsim$. Interrogando a ciência: a concepção vidaliana de Geografia. Confins [On line], 8 (2010b). URL: http://confins.revues.org/6295

ઇ ઇ ઇ Território, Império e Nação: a geopolítica em Paul Vidal de la Blache. Revista da Anpege, n.6 (2010a).

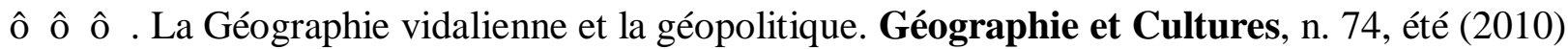

ð $\succsim$. Para ler Geografia ou A Geografia segundo Lucien Febvre. Terra Livre, n.32, ano 25 (2009).

ઇ $\succsim$. Em luta pela autonomia e pelo território: a Geografia e os Estados alemão e francês na virada do século XIX para o século XX. Mercator (UFC), ano 8, n.15 (2009a).

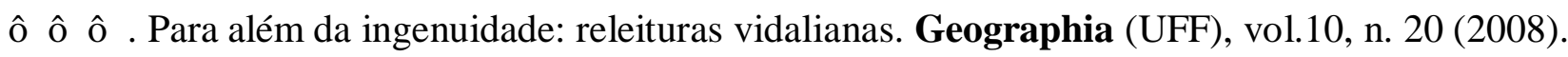

ð $\succsim$. Uma epistemologia em construção: diálogos entre a Geografia e a Sociologia em Paul Vidal de la Blache. Geographia (UFF), vol.9, n. 18 (2007).

ROBIC, Marie-Claire. Lônvention de la ñGéographie Humaineò au tournant des années 1900: les vidaliens et lấcologie. In: CLAVAL, Paul (dir.). Autour de Vidal de la Blache. La formation de lấcole française de Géographie. Paris: Éditions du CNRS (1993).

ઇ . Territorialiser la nation. Le ñTableauò entre géographie historique, géographie politique, géographie humaine. In: ROBIC, Marie-Claire (dir.). Le Tableau de la géographie de la France de Paul Vidal de la Blache. Dans le labyrinthe des formes. Paris: Éditions du CTHS (2000).

ઇ ઇ Note sur la notion dấchelle dans la géographie française de la fin du XIXe siècle et du début du XXe siècle. Cybergeo: revue européenne de géographie, n. 264 (2004).

SANGUIN, André-Louis. Vidal de la Blache et la géographie politique. Bull. Assoc. Géogr. Franç., Paris, 4 (1988).

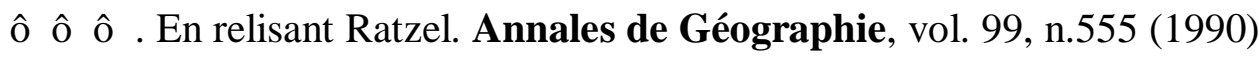

SANTOS, Milton. Por uma Geografia Nova. São Paulo: Edusp (1978).

ઇ ઇ ઇ . A Natureza do Espaço. Técnica e Tempo. Razão e Emoção. São Paulo: Hucitec (1996).

Geo UERJ - Ano 13, nº. 22, v. 2, $2^{\circ}$ semestre de 2011 p. 232-249 - ISSN 1981-9021

http://www.e-publicacoes.uerj.br/index.php/geouerj 
SCHAEFFER, Fred K. Exceptionalism in geography: a methodological examination. Annals of the Association of American Geographers, vol. 43, n. 3, sep. (1953).

SIMIAND, François. Géographie Humaine et Sociologie. LôAnnée Sociologique, tome IX (1909).

SINGARAVÉLOU, Pierre (éd.). LâEmpire des géographes. Géographie, exploration et colonisation (XIXe-XXe siècles). Paris : Belin (2008).

SMITH, Neil. Desenvolvimento Desigual: natureza, capital e a produção de espaço. Rio de Janeiro: Bertrand Brasil (1988 [1984]).

SODRÉ, Nélson Werneck. Introdução à Geografia. Petrópolis: Vozes (1976).

SOJA, Edward. Geografias Pós-Modernas: a reafirmação do espaço na teoria social crítica. Rio de Janeiro: Jorge Zahar Editor (1993 [1989]).

SOUBEYRAN, Olivier. Imaginaire, science et discipline. Paris: LâHarmattan (1997).

VIDAL DE LA BLACHE, Paul. Princípios de Geografia Humana. Lisboa: Cosmos (1954 [1921]).

ð ઇ ઇ . La France de lâEst (Lorraine-Alsace). Paris: La Découverte (1994 [1917]).

ð $\succsim ~ \succsim$. La rénovation de la vie régionale. Foi et Vie: les questions du temps présent n. 9, cahier B (1917)

ઇ $\succsim$. As características próprias da Geografia. In: CHRISTOFOLETTI, Antonio (org.). Perspectivas da Geografia. São Paulo: Difel (1982 [1913]).

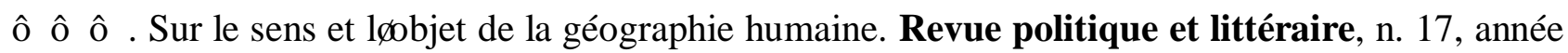
L, avril (1912).

ઇ $\succsim$. Les genres de vie dans la géographie humaine. Premier article. Annales de Géographie, année XX, no 111 (1911). [Uma versão em português deste artigo foi traduzida por Maria Regina Sader e Simone Batista na revista Geographia (UFF), vol. 7, n.13 (2009)]

$\succsim \succsim$. Les genres de vie dans la géographie humaine. Deuxième article. Annales de Géographie, année XX, nº 112 (1911a).

ઇ $\succsim$. La carte internationale du monde au milionième. Annales de Géographie, année XIX, n. 103 (1910).

$\succsim \succsim$. De lônterprétation géographique des paysages. Neuvième Congrès International de Géographie, Genève (1908).

ઇ $\succsim$. La mission militaire française au Pérou. Annales de Géographie, année XV, nº 79 (1906).

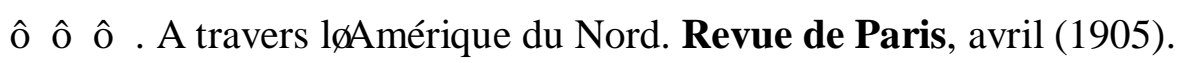

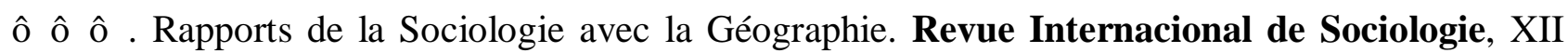
année, n.5, mai (1904). [Uma versão em português deste artigo foi por nós traduzida na revista Confins, n.8 (2010)]

ð $\succsim$. La géographie humaine. Ses rapports avec la géographie de la vie. Revue de synthèse historique, vol. 7, août-décembre (1903a).

ઇ $\succsim$. La France. Tableau géographique. In: RIOUX, Jean-Pierre. Tableaux de la France. Michelet, Duruy, Vidal de la Blache et Bruno. Paris: Omnibus (2007 [1903]).

ઇ $\succsim$. Les conditions géographiques des faits sociaux. Annales de Géographie, année XI, $\mathrm{n}^{\circ} 55$ (1902). [Uma versão em português deste artigo foi por nós traduzida na revista Geographia (UFF), vol. 9, n.18 (2007)]

Geo UERJ - Ano 13, nº. 22, v. 2, $2^{\circ}$ semestre de 2011 p. 232-249 - ISSN 1981-9021 http://www.e-publicacoes.uerj.br/index.php/geouerj 
ઇ $\succsim$. Routes et chemins de lâncienne France. Strates (En ligne). Crises et mutations des territoires, no 9 (1996-97 [1902]) [Uma versão em português deste artigo foi por nós traduzida na revista Geographia (UFF), vol. 8, n.16 (2006)]

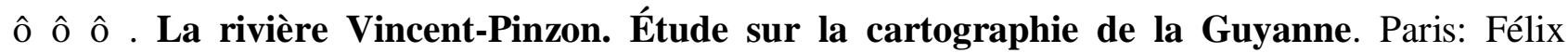
Alcan (1902a)

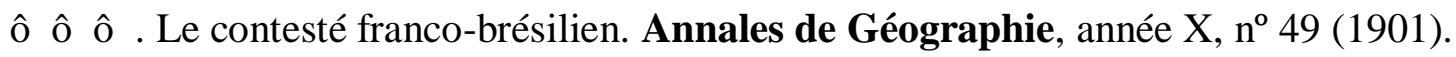

ઇ $\succsim$. Leçon dôuverture du cours de Géographie. Annales de Géographie, VIII année, $\mathrm{n}^{\mathbf{0}} 38$ (1899) [Uma versão em português deste artigo foi por nós traduzida na revista Geographia (UFF), vol. 10, n.20 (2008)]

ð ઇ ઇ . A Geografia Política. A propósito dos escritos de Friedrich Ratzel. Geographia (UFF), $\mathrm{n}^{\circ}$ 7, ano IV (2002 [1898]).

ð $\succsim$. La zone frontière de lôAlgérie et du Maroc, dôprès de nouveaux documents. Annales de Géographie, année VI, nº 28 (1897).

. O Princípio da Geografia Geral. Geographia (UFF), nº 6, ano III (2002 [1896]).

ð $\succsim$. Préface. In: VIDAL-LABLACHE, Paul. Histoire et Géographie. Atlas général. Paris : Armand Colin (1894).

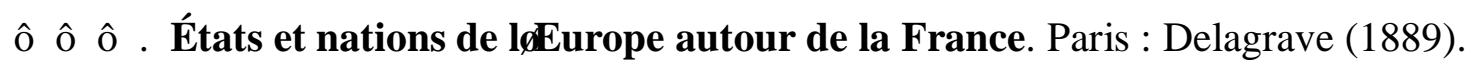

VLACH, Vânia R.F. Acerca da geografia, da política, da geograficidade: fragmentos metodológicos. Sociedade \& Natureza, ano 11, n.21 e 22, jan.dez. (1999)

WERLEN, Benno. Society, Action and Space: an Alternative Human Geography. London and New York: Routledge (1993).

Enviado para publicação em outubro de 2011.

Aceito para publicação em novembro de 2011. 